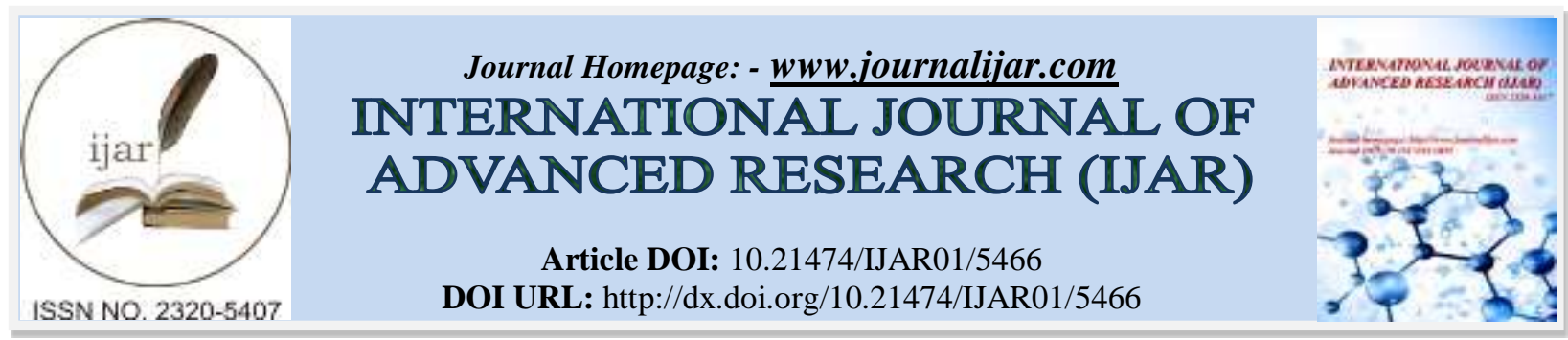

RESEARCH ARTICLE

\title{
EFFECTS OF PLANNING STRATEGIES ON EFFICACY IN THE ADMINISTRATION OF FINANCES IN PUBLIC ECDE CENTRES IN UASIN-GISHU COUNTY, KENYA.
}

\author{
Jane Jelimo Michael ${ }^{1}$, Prof. Catherine Kiprop ${ }^{2}$ and Dr. David Kiprop ${ }^{1}$. \\ 1. Faculty of Education and Human Resource Development, Kisii University. \\ 2. Department of Education Management and Policy Studies, Moi University.
}

\section{Manuscript Info}

Manuscript History

Received: 18 July 2017

Final Accepted: 20 August 2017

Published: September 2017

Key words:-

Planning, Management, Strategy, Efficacy.

\begin{abstract}
Early childhood education is the basis upon which all levels of education are anchored and therefore effective financial management systems are required to maximize the efficient use of resources. The aim of this study was to assess planning as a management strategy and its effects on efficacies in the administration of finances in public ECDE centers in Uasin-Gishu County, Kenya. This study adopted a descriptive survey research design using pragmatist paradigm. The sample size was based on Krejcie and Morgan formula. Schools were stratified to their quotas. Furthermore, 224 ECDE teachers,55 headteachers, 55 SMC chairpersons, 1 QASO,1 County chief education officer and 1 County auditor were sampled using stratified, simple random sampling and purposive sampling techniques. The instruments for data collection were interviews and questionnaires and were piloted in Nandi County. Cronbach Alpha coefficient was used to test the reliability of the instruments. Data was analyzed using descriptive statistics such as measures of central tendencies and inferential statistics Pearson Correlation Coefficient analysis. This study found out that there was no budget preparation in pre-schools based on schools' vision. There was a significant correlation between planning strategies and financial management efficacies. The study recommends that there is need for ECDE management committee to: plan for resources early enough before spending to curb waste. The findings will be of great significance to policy makers on understanding the best strategies which if implemented will promote efficacies in the administration of ECDE funds.
\end{abstract}

Copy Right, IJAR, 2017,. All rights reserved.

\section{Introduction:-}

World Bank (2008) considers education financing as an important element which involves investments that produces substantial social and private outcomes. In Africa, UNESCO (2008) observe that, there are four significant motives associated with investment in schooling. First, education is considered significant for economic growth and advancement as pointed out by UNESCO, (2002) and Lewin \& Stuart, (2003) amongst other researchers. This is attributed to the fact that the education offers human capital needed for economic development in various countries. Secondly, education is considered to contribute to the socialization procedures of youth who are considered to have a higher likelihood of losing both the societal and moral ethics (UNESCO, 2004). The constitution of Kenya (2010) 
establishes two levels of government; the National and the County with each given a specific role to perform in the management of education. The National government is concerned with curricula, examinations, policy, standards and granting charters to tertiary institutions. These institutions deal with research, secondary education, special needs education and employment of teachers except management of co-curricular activities. The County governments are concerned with management of early childhood education.

It is important to note that ECDE being the initial stage of setting the learner's foundation, it is required that all stakeholders address critical matters of accessibility, quality, relevance and equity of ECDE programmes (Kibera \& Kimokoti, 2007). Notably, the policy document indicates that, various stake holders are engaged in service provision for learners, yet the resources available are too few for the number of learners requiring the same services. There is need therefore to maximize resources which are available so as to ensure that the ECDE services offered are accessed in an equitable manner, acceptable and socially relevant way. This guarantees for a more efficient coordination of delivery of services among other partners (RoK, 2006).

Many studies however have been conducted on the efficiency of management of secondary funds (Kosgei, 2013; Muofhe, 2012) and found that subsidized secondary education has not been felt in some parts of the country. Other studies on challenges that affect the management of Free Primary Education funds (FPE) (Owiti, 2010; Okumu, 2014; Muthangya, 2012) and Jane, Rotich \& Kiprop, (2014) on challenges of implementing the procurement policy in public primary schools indicate that compliance is still questionable and many learning institutions have not adhered to the procurement guidelines and best practices of financial administration. Although these studies have addressed the implementation and challenges affecting financial management in secondary and primary school sections, they have not addressed the effects of management strategies on efficacies in financial administration in public ECDE centres, an issue which this study sought to look at. It was therefore necessary that a study of this nature be undertaken hence provide information geared towards improving efficiency in financial management.

\subsection{Literature Review:-}

Financial planning is an organizational framework tool which is used to ensure that funds is available at the right time and for the right purpose following clearly laid guidelines of spending in order to cater for the needs of the institution both short term, medium or long-term. In essence, capital and financial control aims at assessing whether the plan put forward meets the objectives of the institution (Tooley \& Hooks, 2009). It is prudent that any person, corporation, or institution knows what they require and the means to get it (Clark \& Krentz, 2004). The planning process uses analytical models that provide a practical picture of the corporation, institution or individual. Policy documents regulating on practice have charged head teachers of public learning institutions to be in-charge of all funds (accounting officers). In other words, the head teachers are the chief guardians of school resources and are key in the execution of approved budgets.

Motsamai, Lynette and Corene (2011) found in their studies that head teachers have to administer and manage all issues in their schools including financial administration. In Kenya, Section 21 of the Education Act of 2010 (MOET, 2010), the head teacher- is the main accounting officer of a learning institution and is accountable to board of management on all issues of administration and more so the control and use of school funds. The major role of head teachers being maintenance of all records of income and expenditure of the school; preparation of an annual budget for the school though in collaboration with the BOM and submission of the same to the school board for its approval.

According to Yambo, Odhiambo \& Odera (2014), the administration of school resources encompasses the task of Planning which involves budgeting, coordinating, leading as well as controlling. Their view is that a school's efficient financial administration is imperative since it enables learning institutions to attain quality education and more so when the school budget is strictly adhered to.

Professional financial planning is an important option for overall financial well-being. Financial planners have tools and expertise which in many occasions is a skill not acquired by the general population. Such skills are essential and can help schools facing complex circumstances make informed choices on financial spending. In addition, Collins (2010) in his study outlines four different roles that financial planners can play: coach, counselor, technical expert, and transactional agent. Given the wide spectrum of these vital roles, the outcome measures from financials spending can be of great benefit to planners though to some extent variations maybe experienced. 
Cole and Kelly (2011) define planning as the formalization of what is intended to happen at some point in the future; it includes suggestions of actions that need to be undertaken before to an occurrence and typically involves formulation of goals, setting achievable objectives and pooling resources together so as to attain the anticipated outcomes. In essence, planning translates to budgeting which is usually articulated in financial terminologies of the anticipated achievement of a learning institution so as to attain set goals. A budget is an action plan for the immediate future, representing the set and tactical end of the corporate planning chain.

Financial planning of school finances and its control are mutually supporting and closely linked with each other as supported by Ntseto (2009). It can therefore be concluded that, the same relationship exists between the budget and control system since a budget is a planning instrument to be used as a means for control. The effects of financial administration and its impact on institutional performance was put into perspective by (Ahmed, Babar \& Kashif, 2010).

In another study, Barasa (2009) recognizes that efficiency of financial administration as a crucial responsibility for head teachers. Moreover, lack of adequate financial resources may affect institutions' ability to carry out their roles in an effective way. Emphasis is that finances need to be availed to allow for smooth running of school activities based in all the departments. The available funds are used to procure the necessary teaching and learning materials like chalks, textbooks, paying of the support staff, building and renovation of existing infrastructure.

\section{METHODOLOGY:-}

\subsection{RESEARCH DESIGN}

Research design according to Creswell (2009) is a plan and the procedure for research that extent the decisions from broad expectations to detailed approaches of data collection and analysis. The current study adopted a descriptive survey design. In addition, Kombo and Tromp (2009) points out that a descriptive survey design enables the investigator to describe the state of activities as they are and report the findings accordingly. Moreover, descriptive surveys allow rapid collection of data from a large sample within the shortest time possible by use of questionnaires, interview schedules and document analysis. In addition, the study adopted convergent mixed methods using pragmatist paradigm for it was considered to be useful in helping researcher meet the criteria for estimating the goodness of their answers in better way as compared to those of single strategy designs (Tashakkori \&Teddlie, 2003).

\subsection{TARget Population}

Population denotes the entire group of subjects including the entire number of environments which are considered to be of concern to the investigator (Oso \& Onen 2008). The research targeted all public ECDE centres in Uasin-Gishu County. The region has 576 public ECDE centres. All the 1728 ECDE teachers, 422 headteachers and 422 SMC chairpersons, 1 County quality assurance and standards officer, 1 County chief education officer and 1 County auditor form the study population of 2575 .

\subsection{SAMPLE SIZE}

A total of 2572 respondents consisting of 1728 ECDE, 422 head teachers and 422 SMC chairpersons were used to get a sample size for the research. This research was based on a sample size determination formula advanced by Krejcie and Morgan (1970) as cited by Kasomo (2001). The total sample size for the study is indicated in Table 1.

Table 1:- The Sample Size for Respondents

\begin{tabular}{|l|c|c|}
\hline Category & Target population & Sample size \\
\hline ECDE Teachers & 1728 & 224 \\
\hline Headteachers & 422 & 55 \\
\hline SMC Chairpersons & 422 & 55 \\
\hline County Quality Assurance Officer & 1 & 1 \\
\hline County ECDE director & 1 & 1 \\
\hline Auditor & 1 & 1 \\
\hline Total & 2575 & 337 \\
\hline
\end{tabular}




\subsection{Sampling Techniques}

In selecting ECDE centres included in this research, stratification was used to place ECDE centres in their quotas; Kesses sub-county 35, Kapseret Sub-County 28, Ainabkoi Sub-county 26, Moiben Sub-County 30, Turbo Subcounty 48 and Soy Sub-County 64 totaling to 231 ECDE centres. Stratification guaranteed that each individual stratum was assigned the proportionate number of ECDE centres as in the population.

Pre-schools which were placed in each stratum were randomly carefully chosen by using specific codes to identify them. The researcher assigned a unique code to each ECDE centre for identity. Stratified simple random sampling was also used to select ECDE centres to participate in the study. stratification guaranteed that each ECDE centre in each stratum had an equal chance to be included in the sample. The QASO, the County chief education officer, Headteachers, SMC chairpersons and the County auditor were purposively sampled.

Moreover, 224 ECDE teachers were chosen through the adoption of simple random sampling procedure. This procedure ensured that all the members of the population are given an equal chance of being included in the sample. The outcomes attained from the use of probability or random sampling procedures can be assured in terms of likelihood for instance errors of estimation or the significance of outcomes obtained from a random sample can be measured. This circumstance brings out the advantage of random sampling strategy over the purposive sampling strategy (Kothari, 2008).

\subsection{RESEARCH INSTRUMENTS}

Researchers like Kombo and Tromp (2006) posit that in social science, interviews questionnaires, observation checklists and standardized evaluations are commonly used as research tools. Structured interview was administered to County Quality assurance and standards officer, the County chief education officer and the County auditor in order to understand better issues of financial administration efficacy in public ECDE centres. A great deal of qualitative is obtained from talking with individuals either through formal interviews or through casual conversations. Questionnaire was the main tool used to gather research information from the primary school head teachers, SMC chairpersons and ECDE teachers. Kothari (2008), postulated that questionnaires are normally free from the interview predisposition as the answers from the respondents are in respondents' own words. In addition, research participants also have sufficient time to give well thought out answers.

\subsection{VALIDITY AND RELIABILITY OF THE RESEARCH INSTRUMENTS}

Validity according to Kothari (2008) is the correctness, accuracy, meaningfulness of implications and dependability of outcomes of conclusion, which are based on the research findings. The researcher sought expert views on both content and construct validity of the research instruments. Comments besought from them were used to enhance the study's instrument before beginning on data collection procedures.

To determine the reliability of the instruments, teachers' questionnaires and SMC chairpersons were piloted using 30 public ECDE teachers and SMC chairpersons in Nandi County who were not part of this research study. The testretest strategy was adopted to test the reliability of questionnaires. The Pearson's Product Moment Correlation (r) was used to calculate the reliability coefficient between the first and second scores. The coefficient attained was then transformed into a suitable correlation for the entire test by use of the Spearman and Brown prophecy formula. A correlation coefficient of (r) 0.75 or more was considered appropriate to establish the reliability of the research instruments as indicated by Orodho (2009). In this research, a correlation coefficient of 0.78 was attained showing that the tools were dependable and therefore were deemed fit for collection of data.

\subsection{DATA ANALYSIS}

Analysis of data involves interpretation, organization and presentation of collected information so as to decrease the information collected from the field to be practical (Onen \& Oso, 2005). Data obtained was analyzed using quantitative and qualitative techniques. The quantitative data from the questionnaire were first subjected to preliminary processing through validation, coding and tabulation in readiness for analysis with the help of the statistical package for social science (SPSS) computer package as a 'toolbox' to analyze data related to objectives. Frequencies, percentages, mean and Standard deviation was used to analyze quantitative data. Pearson Correlation Coefficient was employed to determine relationship that exists between the independent (planning,) variable and dependent variable (financial efficacies). Qualitative data from interview schedules was transcribed, thematically classified and arranged before they were reported in narrations and quotations. 


\subsection{ETHical Considerations}

Hesse-Biber \& Leavey, (2007) notes that participants in research are required to versed with ethical requirements in order to safeguard information obtained from their respondents. Before commencing on collecting data, the investigator required a research permit from the National Commission for Science, Technology and Innovations (NACOSTI). In addition, permission was sought from County Director of Education and head teachers of the selected primary schools which houses the ECDE centres before conducting the study. The respondents' involvement in the study was voluntary and free. There was no promise of benefits for involvement in the study and the respondents were asked to sign the informed consent form. The participants were further guaranteed that information given would be treated private and confidential as it was meant for this study only. In addition, the participants were also informed that they were free to withdraw from the study at any time they deem fit.

\subsection{Study Findings:-}

The aim of this study was to establish planning strategies employed and its effects on financial management efficacies in public ECDE centres in Uasin-Gishu County. Financial planning is important in meeting the objectives of the organization in question (Tooley \& Hooks, 2009). To realize this objective, the participants were requested to rank their degree of agreement on a three-point likert scale items. The outcome of information analyzed are shown in Table 2.

Table 2:- Responses on Financial Planning Strategies Employed

\begin{tabular}{|l|l|l|l|l|l|l|}
\hline Statement & \multicolumn{2}{|c|}{ D } & \multicolumn{2}{|c|}{ UD } & \multicolumn{2}{|c|}{ A } \\
\cline { 2 - 6 } & F & $\%$ & F & $\%$ & F & $\%$ \\
\hline The pre-school prepares its budget based on the school's vision & 190 & 61.5 & 26 & 8.4 & 93 & 30.1 \\
\hline $\begin{array}{l}\text { Stakeholders' decisions are taken care of during budgetary making process in } \\
\text { the pre-school }\end{array}$ & 196 & 63.4 & 10 & 3.2 & 103 & 33.3 \\
\hline The pre-school budgets are flexible and realistic & 233 & 75.4 & 20 & 6.5 & 56 & 18.1 \\
\hline $\begin{array}{l}\text { The SMCs have high levels of financial knowledge making them to make } \\
\text { more fiscally responsible decisions }\end{array}$ & 227 & 73.5 & 0 & 0.0 & 82 & 26.5 \\
\hline The budgeting process in our school is based on priorities & 114 & 36.9 & 23 & 7.4 & 172 & 55.7 \\
\hline Pre-school budgets are adequately compiled at the start of every term & 186 & 60.2 & 28 & 9.1 & 95 & 30.7 \\
\hline Bank reconciliation statements are always compiled by the SMCs & 215 & 69.6 & 23 & 7.4 & 71 & 23.0 \\
\hline
\end{tabular}

Table 2 shows that 190(61.5\%) respondents disagreed with the statement that their pre-schools prepare its budget based on the school's vision, 93(30.1\%) respondents agreed with the statement while 26(8.4\%) were not decided on the view. Results showed that majority $(61.5 \%)$ of the respondents reported that in their pre-schools there was no budget preparation based on their schools' vision. This implies that most ECDE centres carry out their financial transactions without budgetary allocations. This is attributed to the limited finances in ECDE centres owing to the fact that parents are the major financers of ECDE programmes and the economic backgrounds affect cashflows in the centres. Lack of budget preparation is also affected by unpredictable financial performance hence finances are utilized as they come. This implies that planning plays an integral role in promoting efficacies in the administration of resources in ECDE centres without which misappropriations or neglect of various programmes may arise. This is in cognizance with the findings of Lynch et al., (2010) which found out that future oriented, planning behaviors are associated with an array of positive financial outcomes.

In addition, 196(63.4\%) respondents disagreed that stakeholders' decisions are taken care of during budgetary making process in the pre-school, 103(33.3\%) respondents agreed with the view while 10(3.2\%) respondents were not decided on the statement. The study findings suggested that majority $(63.4 \%)$ of the respondents believed that stakeholders' decisions were not taken care of during budgetary making process in the pre-school. This is attributed to the fact that the management committee operate on slim budgets and are forced to go for the most pressing needs. It also implies that financial status of the institution will dictate decisions which are made during budgetary making process some which may not be in line with the suggestions proposed by the various education stakeholders. This is likely to discourage the stakeholders from supporting ECDE programmes yet they are the major financiers of ECDE programmes. This is in agreement with the Government of Western Australia (2015) on Engagement Guidelines for Community Services Procurement which indicated that undertaking stakeholder engagement in a collaborative and transparent way allows the government agency to build and maintain strong relationships with stakeholders, demonstrates accountability and contributes to better outcomes for the community. 
Interviews conducted found out that planning of finances was important for achievement of vision and mission defined by ECDE management. One of the head teachers interviewed indicated that planning is an important aspect in meeting the targets set by the school management and therefore there is need to understand areas where more or less finances need to be involved. In addition, it emerged that planning enabled ECDE centres to incorporate changes in their short-term and long-term plans (goals). This concurs with Nickols (2016) who noted that planning as a strategy enhances the achievement of one's goals and objectives. This points out that, planning is an important tool for implementation of ECDE programmes.

Furthermore, it emerged that there was participation of stakeholders in planning of ECDE programmes in the study. This allows stakeholders, teachers, parents and community to participate in development of ECDE Centre or school during planning and implementation therefore owning their own programmes. This is in agreement with the guideline manual (MOE, 2006) which defines the responsibilities education stakeholders such as the community, parents, government ministries and departments, development partners and amongst other stakeholders in the provision of ECDE services.

Further, 233(75.4\%) participants were in disagreement with the statement that the pre-school budgets are flexible and realistic, 56(18.1\%) respondents agreed with the statement while 20(6.5\%) respondents were not decided on the statement. The results showed that majority (75.4\%) of the respondents were of the view that their pre-schools' budget were not flexible and realistic. This shows that most budgets in ECDE centres are not realistic or flexible owing to the fact that the centres are majorly dependent on funds from parents who might delay in paying fees rendering budgets to be slim, non-realistic hence not flexible. This forces the management to go for the most pressing needs which might be against budgetary plans. This is in cognizance with the works of Lucy (2003) who posit that planning is realized through a fixed master budget. However, control strategy is mostly achieved through the comparison of actual cost with an elastic budget. This indicates that most ECDE centre budgets are not effectively implemented hence compromising on financial efficacies.

This is further in agreement with Coles and Kelly (2011), who noted that management administrators in-charge of implementing financial plans need to participate in the formulation and attainment of a flexible budget that can withstand the ever-fluctuating conditions. Flexible budgets should be seen as a means to an end and not an end in them. Moreover, Clarke, (2007) and Du Pereez et al. (2003), have it that financial plans are straight forward-looking procedures which should be dictated by the schools' vision and mission for the future and realistic evaluation of unforeseen challenges. In addition, financial plans are accomplished into a solitary unifying statement of the organization's potentials for imminent time periods, (Drury, 2001). This shows that management committees should draw flexible budgets that can survive the unexpected changes that impact on financial flows which are inevitable so that ECDE center programmes can still run as scheduled.

Similarly, 227(73.5\%) respondents disagreed with the statement that the SMCs have high levels of financial knowledge making them to make more fiscally responsible decisions, $82(26.5 \%)$ respondents agreed with the statement. The study outcomes showed that majority (73.5\%) of the respondents reported that SMCs in-charge of ECDE centres did not have adequate financial management knowledge and this could have a negative effect on financial management decision making process in public ECDE centres. This is attributed to their levels of education and lack of training and exposure on issues of financial administration. When this happens uninformed decisions on financial spending might be made leading to compromise on financial spending. In such a case, the little available resources might be wasted as programmes in ECDE centers collapse or may not be sustained hence deny learners access to basic education. This is consistent with Robb and Woodyard, (2011) who assert that having financial skills does affect individuals to behave in some more financially responsible ways. Majority of the SMCs had little knowledge and skills on financial management, this causes a challenge on resource management which results to shortcomings on financial efficacies in ECDE centres.

In addition, 172(55.7\%) respondents agreed that the budgeting process in their schools was based on priorities, $114(36.9 \%)$ respondents disagreed while $23(7.4 \%)$ respondents were undecided. This shows that majority (55.7\%) respondents believed that budgeting in the schools was based on the priorities of the schools. This is an indicator that ECDE centres are being guided by the most pressing needs during the budgeting process and may not be able to adhere to the budget as required. This is in cognizance with the work of McKinney as cited in Motsamai (2011) who points out that financial planning is a continuous and dynamic procedure which is marked by regular steps which include needs assessment planning, and prioritization of activities. However, this was found contrary to Kruger 
(2005) who noted that rather than prioritizing expenditure in a tight financial plan based on estimated income and expenses, various pre-school committee members relinquished even before trying to draw up a representative financial plan. This could be attributed to the in availability of resources as indicated by headtechers interviewed who felt that ECDE programmes are underfunded and mostly financial support came from parents through payment of fees.

Moreover, $186(60.2 \%)$ participants were in disagreement with the view that pre-school budgets are adequately compiled at the start of every term, 95(30.7\%) respondents agreed with the statement while 28(9.1\%) respondents were undecided with the statement. Results indicated that a majority $(60.4 \%)$ of the respondents were of the opinion that pre-school budgets were not adequately compiled at the start of every term. This was attributed to the everarising needs and unpredictable financial performances which made them not to be in a position to make financial plans as required. This implies that there is poor compilation of financial reports hence a hindrance to the tracking of financial performance in most ECDE centres. When this is the case it may provide a leeway for misappropriation, or embezzlement of public resources therefore denying learners of quality services. This is consistent with Mestry (2006) who found out in his study that learning institutions in South Africa, had poor or non-existent compilation of financial reports.

Further, 215(69.6\%) respondents disagreed with the statement that bank reconciliation statements are always compiled by the SMCs, 71(23\%) participants agreed with the statement and 23(7.4\%) respondents were not decided on the view. Results further suggested that majority $(69.6 \%)$ of the participants believed that bank reconciliation statements were not always compiled by SMCs. This is attributed to lack of training on financial management skills hence SMCs are not in a position to perform their tasks accordingly. For SMCs to compile financial returns, they need to be trained on financial management which will influence their performance positively enhancing efficacies in financial management in ECDE centres. This is also in cognizance with a study by Owens (2006) who indicated that training is known to be a tool that can assist learning institutions to develop skillful, committed, pro-active and productive workforce.

\section{1 Relationship between Planning Strategies and Financial Management EfFicaCiES}

The hypothesis that guided this study states that:

$\mathbf{H O}_{1}$ : There is no significant relationship between planning strategies employed and financial management efficacies in public ECDE centres in Uasin-Gishu County.

Pearson Correlation Coefficient (simply, $r$ ) was employed to determine the potential relationship between planning strategies applied and financial management efficacies. Table 3 presents the correlation coefficient between planning strategies employed and financial management efficacies.

Table 3:- The Correlation Coefficient between Planning Strategies Employed and Financial Management Efficacies

\begin{tabular}{|l|c|}
\hline \multirow{3}{*}{ Planning } & Financial Efficiencies \\
\cline { 2 - 2 } & $\mathrm{r}=-.826^{* * *}$ \\
\cline { 2 - 2 } & $\mathrm{p}=.000$ \\
$\mathrm{n}=309$
\end{tabular}

**. Correlation is significant at the 0.01 level (2-tailed).

Table 3 shows that a significant very strong negative correlation $(r=-.826 ; p=.000)$ between planning strategies employed and financial management efficacies in public ECDE centres in Uasin-Gishu County. The study findings therefore showed that there was a significant relationship between financial planning and financial efficacies. Therefore, the null hypothesis which stated that; there is no significant relationship between planning strategies employed and financial management efficacies in public ECDE centres in Uasin-Gishu County was rejected and the alternate accepted. The study negative correlation implies that the board of management of ECDE centres could be lacking adequate financial planning skills or could be hampered by financial constraints to laxity in the implementation process. Results therefore indicate that there is a statistically significant but negative relationship between planning strategies employed and financial management efficacies.

This concurs with the works of Lane, Bishop, and Jones (2005) who pointed out that strategic execution in learning institutions creates the trend to the realization of the desired goals including the schools' vision and mission. In another study by Thompson, Strickland and Gamble (2007), it emerged that the core of good policy making is to shape a market position which is strong enough in a learning institution skilled enough to yield effective 
performance notwithstanding unforeseeable actions, potential competition and internal challenges. This shows that planning of programmes in ECDE centres could enable effective execution of the same programmes.

In addition, responses from the auditor indicated that most ECDE centres do not make budgets and if made they are not realistic since money streams into schools' accounts in bits hence schools will use resources for the most pressing needs. In addition, the auditor cited poor planning mechanism as an obstacle for financial efficiency in that most schools had issues concerning the budget or there were a lot of defaults on issues of fees payment. The auditor noted that there was need for training of SMCs to boost ability to utilize funds placed in their hands. The county director had the opinion that most SMCs are illiterate and lacked competence in financial management. Moreover, others planned way too long after using the funds. This was found to be in agreement with a report from World Bank (2010), which revealed that most schools struggle with little finances that come mostly from collection of fees which the parents pay. In situations where schools are located in areas of low economic grounds like sum and rural settings situations would be worse.

The QASOS (CSOS) observation was attributed to poor monitoring of spending and poor planning strategies, that money spent was not commensurate to the cash inflow. This is contrary to the works of Clarke (2007) and Preez et al (2003) who pointed that the financial planning for all the numerous decisions are expressed in terms of inflows and outflows of cash, sales and relevant revenues and expenditures incurred. It was proposed that the government should inject more resources to support ECDE programmes and frequent monitoring strategies be set to curb waste.

\section{CONCLUSIONS AND RECOMMENDATIONS:-}

The research found out that there was a significant but negative correlation between planning strategies and financial management efficacies in public ECDE centres in Uasin-Gishu County. The results showed that there was no budget preparation based on schools' vision, that stakeholders' decisions were not taken care of during budgetary making process in public pre-schools, that public pre-schools' budgets are neither realistic nor flexible, SMC in-charge of ECDE centres did not have adequate knowledge on financial management, that budgeting in the schools was based on the priorities of their schools, pre-school budgets were not adequately compiled at the start of every term and finally SMCs had inadequate skills in financial management. It can therefore be concluded that planning strategies are not adhered to in most public ECDE centres hence compromising the administration of financial management efficacies in public ECDE centers in Uasin-Gishu County.

Results indicate that most public ECDE Management Committees do not adequately plan for their finances as this was shown to negatively affect financial efficacies. It is therefore recommended that there is need for the government to increase and be consistent and also disburse funds in time so that ECDE management committee can make budgets on time before spending.

\section{REFERENCES:-}

1. Ahmed, I. H., Babar, Z.B., \& Kashif, R. (2010). Financial management practices and their impact on organizational performance. World Applied Sciences Journal, 9(9), 997-1002.

2. Barasa, J.M.N. (2009). Educational Organisation and Management. Nairobi; Jomo Kenyatta Foundation.

3. Clark, C.S.\& Krentz, S.E. (2004). Avoiding the Pitfalls of Strategic Planning. Healthcare Financial Management, 60, no. 11 63-68.

4. Clarke, A. (2007). The Handbook of School Management. Cape Town: Kate McCallum.

5. Cole, G.A. \& Kelly, P. (2011). Management: Theory and Practice 7th Edition UK; engage learning EMEA.

6. Collins, J. M., \& O'Rourke, C. M. (2010). Financial education and counselling still holding promise. Journal of Consumer Affairs, 44, 483-498.

7. Creswell, J. W. \& Plano-Clark, V. (2009). Designing and Conducting Mixed Methods Research. Thousand Oaks, CA.: Sage.

8. Drury, C. (2001). Management Accounting for Business Decisions. Thompson Learning, London pg. 4, 17

9. Government of Kenya (2005). Sessional Paper No. 1: A Policy Framework for Education Training and Research. Government Printers, Nairobi, Kenya.

10. Hesse-Biber, S. N., \& Leavy, P. L. (2007). Feminist research practice: A primer. Thousand Oaks, CA: Sage.

11. Jane, J. M., Rotich, S.K. \& Kiprop, C (2014). Challenges facing school board of management in the implementation of the procurement policy in Kenya. Global Journal of Interdisciplinary Social Sciences, 3(3), 104-112. 
12. Kasomo, D. (2001). Research Methods in Humanities and Education. Njoro, Egerton University Press.

13. Kibera, W. K \& Kimokoti, A. (2007). Fundamentals of Sociology of Education with Reference to Africa. Nairobi: University of Nairobi Press.

14. Kothari, C. R., (2008). Research Methodology: Methods and Techniques ( ${ }^{\text {nd }}$ Ed).Age, New Delhi, International publishers.

15. Krejcie, R. V, \& Morgan, D. W. (1970). Determining sample size for Research Activities. Educational \& Psychological measurement,30, (1) 607-610).

16. Lewin. K . M., (2008). Strategies for Sustainable Financing of Secondary Education in Sub-Saharan Africa. Africa Human Development Series. Working Paper No 136. World Bank, Washington.

17. Lucey, T. (2003) Management Accounting 5th Edition. Book Power, London.

18. Mestry, R. (2004). Financial accountability: The principal or the school governing body. South African Journal of Education, 24: 126-134.

19. MOET (2010). Education Act 2010. (Act No. 3of 2010). Lesotho Government Gazette Extraordinary, 55(3). Maseru: Government Printers.

20. Motsamai, J. M., Lynette, J. \& Corene, de W. (2011). Policy and Practice: Financial Management in Schools in Mafeteng District of Lesotho. Journal of Social Science, 26 (2) 105-116.

21. Nickols F (2012). Strategy Definition and Meaning. Distance Consulting LLC. Retrieved from http//www.nickols.us.12 ${ }^{\text {th }}$ April, 2017.

22. Ntseto, V. E. (2009). A Programme to Facilitate Principals" Financial Management of Public Schools. Ph.D. Thesis, Unpublished. Bloemfontein: University of the Free State.

23. Okumu, R (2014). Management of Free Primary Education Funds in Kenya. LAP LAMBERT Academic Publishing, London.

24. Orodho, J. A. (2009) Elements of Education and Social Sciences Research Methods. Maseno, Kenya: Kanezja publishers.

25. Owens, P. L. (2006). One more reason not to cut your training budget: The relationship between training and organization outcomes. Public personnel management, 35(2), p.163-171.

26. Owiye, J. (2010). Management of resources in ECDE centres and its implications on quality of ECDE in Bungoma East District. Unpublished M.Ed thesis. Masinde Muliro University of Science and Technology.

27. Oso W.K \& Onen D. (2008). A General guide to writing research proposals and report. (2 $2^{\text {nd }}$ ed) Kampala: Makerere University.

28. Pearce, A. \& Robinson, R.B. (2000). Formulation, Implementation, and Control of Competitive Strategy. New York: Irwin McGraw-Hill.

29. UNESCO (2005). Policy Review Report. ECE in Kenya. Paris. UNESCO.

30. World Bank (2008). World Development Indicators 2008-09. Washington DC. World Bank.

31. World Bank, (2010). Educational Notes, Education For All. Amazon; World Bank Publications.

32. Yambo, J. M. O., Odhiambo, R. A. \& Odera, Y. F. (2014). An Assessment of the Extent at which High School Principals are Stressed in relation to their Job Experience in Schools in Southern Nyanza Region, Kenya. International Journal of Humanities and Social Science Invention ISSN (Online): 2319 -7722, www.ijhssi.org3 (5) 25-33. 